\title{
LA NECRÓPOLIS Y EL ÁREA SACRA IBÉRICOS DE «LAS AGUALEJAS» (MONFORTE DEL CID, ALICANTE)
}

\author{
LORENZO ABAD CASAL \\ FELICIANA SALA SELLÉS \\ ELIA M. ${ }^{\text {a }}$ ALBEROLA BELDA \\ Universidad de Alicante
}

\begin{abstract}
En este artículo se estudia un conjunto de manchas con cerámicas ibéricas que parecen corresponder a desechos de ceremonias rituales relacionadas con la necrópolis vecina, donde se encontró el célebre pilar-estela.

In this paper we have studied a set of spots full of Iberian pottery, which seems to belong to leftowers from ritual ceremonies related to the neighbouring necropolis, where the famous stele-pillar was found.
\end{abstract}

En el verano de 1987 uno de los firmantes (EAB) tuvo conocimiento de que durante una remoción de tierras efectuada en la orilla izquierda del Vinalopó, en el término de Monforte del Cid, se habían producido hallazgos arqueológicos (Figs. 001 y 002). El paraje es conocido por haber proporcionado numerosos restos antiguos, tanto ibéricos como romanos (GALIANA y ROSELLO, 1984-85; LLOBREGAT y RIBELLES, 1978, 24 ss.; ABASCAL, 1988, 361 ss)' ${ }^{1}$ y en sus inmediaciones se había encontrado años atrás los restos del monumento turriforme expuesto hoy en el Museo Arqueológico de Elche y del toro conservado en el Ayuntamiento de Monforte. La remoción de tierras había afectado a una capa de más de un metro de profundidad cuando, con el permiso preceptivo de la Conselleria de Cultura, se comenzó el seguimiento arqueológico (ABAD y ALBEROLA, 1990, 17 ss; ABAD y SALA, 1992, 158). En el perfil, a unos $45 \mathrm{~cm}$ de altura, existía un nivel de tierras cenicientas con cerámicas romanas. Lo más significativo se encontraba,

\footnotetext{
${ }^{1}$ Hasta el momento no se han realizado excavaciones sistemáticas en este paraje; el único intento emprendido, hace ya algunos años, no dio resultado positivo, pues la parcela donde se excavó, que presentaba abundante material arqueológico en superficie, resultó haber sido rellenada con tierra de acarreo, aunque ya se hubiera perdido la memoria de esta acción. Cf. Abad, 1986, $106 \mathrm{~s}$.
} 


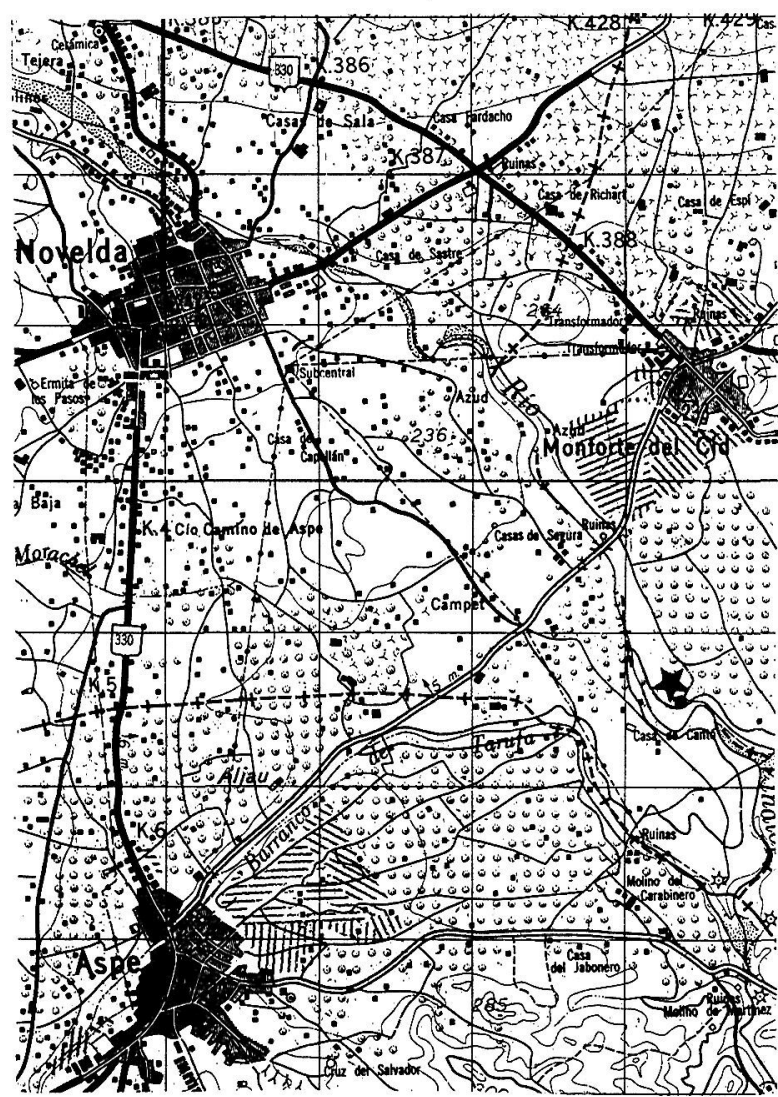

Fig. 1. Ubicación del yacimiento.

no obstante, en la superficie dejada tras la remoción, donde podía observarse un conjunto de manchas cenicientas y una estructura cuadrangular de piedras que identificamos con un túmulo, todo ello asociado a cerámicas ibéricas de diferentes tipos. En ninguna de las manchas se encontraron restos humanos que pudieran relacionarlas con cremaciones; los pocos huesos documentados son de origen animal. Resultaba evidente, por tanto, que en este lugar existieron dos momentos de ocupación, uno ibérico y otro romano, separados por un amplio hiatus temporal ${ }^{2}$.

\section{ÉPOCA IBÉRICA}

\section{Mancha 1}

Esta mancha fue la que dio mayor cantidad de materiales, debido a que se encontraba al final de la rampa que el tractor utilizaba para bajar desde la parcela contigua. La totalidad del material arqueológico recuperado son fragmentos de vasos cerámicos y destaca la ausencia de objetos metálicos, hecho que constituye una constante en el yacimiento.

La cerámica pintada se reduce a fragmentos de bordes de

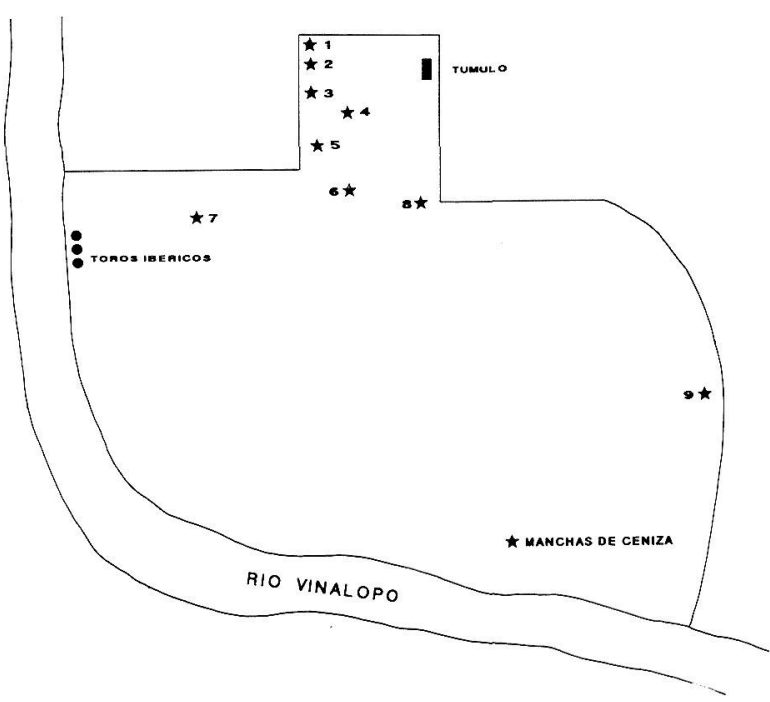

Fig. 2. Ubicación de las estructuras.

urnas y paredes de platos de pequeño tamaño; la abundancia de perfiles de sección subtriangular, algunos de ellos moldurados, permite encuadrarlos en la fase ibérica antigua, momento en el que estos perfiles son los más característicos. La decoración se limita a bandas y filetes, hecho que corrobora, hasta cierto punto, la atribución propuesta.

La cerámica común, tan abundante como la pintada, está representada también por platos y urnas. Los platos resultan de especial valor al compararlos con el repertorio de El Oral; como ocurre en este poblado, los más abundantes son los de cuerpo de casquete semiesférico y borde simple ligeramente reentrante (tipo PlA) (Fig. 003, 1-7, 8-9, 12, 16); también se encuentran algunos ejemplares de borde exvasado similares a las formas P2A y P2C (Fig. 003, 10-11) (ABAD y SALA, 1993, fig. 163), que desaparecen en la fase ibérica plena. Otra pieza destacable es un fragmento de tapadera de orejetas (Fig. 003,13 ), forma que, aunque perdura hasta la primera mitad del s. IV a. C., es más representativa de los contextos materiales de cronología antigua.

La cerámica de cocina está representada por bordes de olla cuyos perfiles, también de sección subtriangular, vienen a confirmar la argumentación tipológica realizada hasta ahora, aunque el conservadurismo de este tipo de producción cerámica —que todavía sigue creando estos mismos perfiles en la

\footnotetext{
2 Una versión más completa de este trabajo, que incluye el inventario de todo el material aparecido, ha sido depositada en el Servicio de Arqueología y Etnología de la Consellería de Cultura de la Generalitat Valenciana.
} 

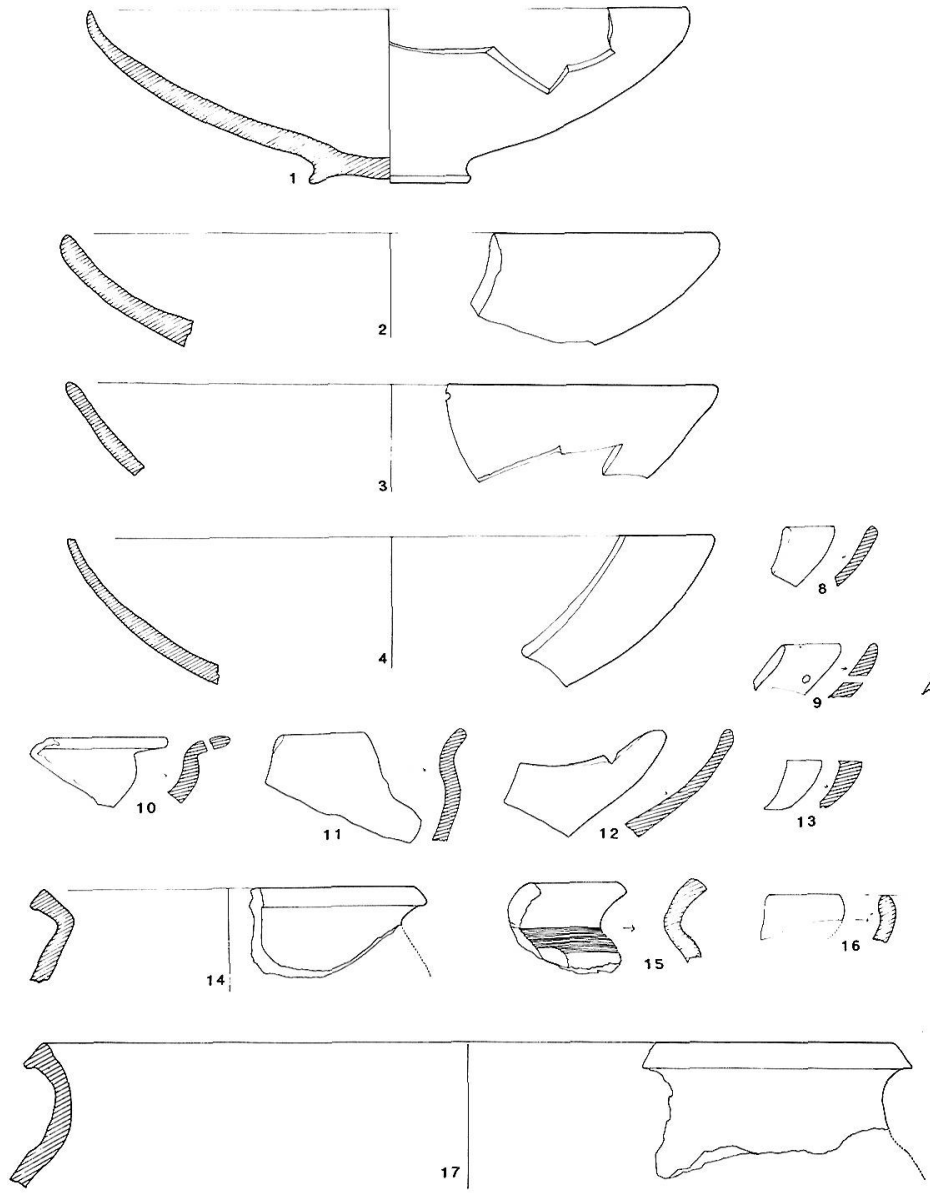
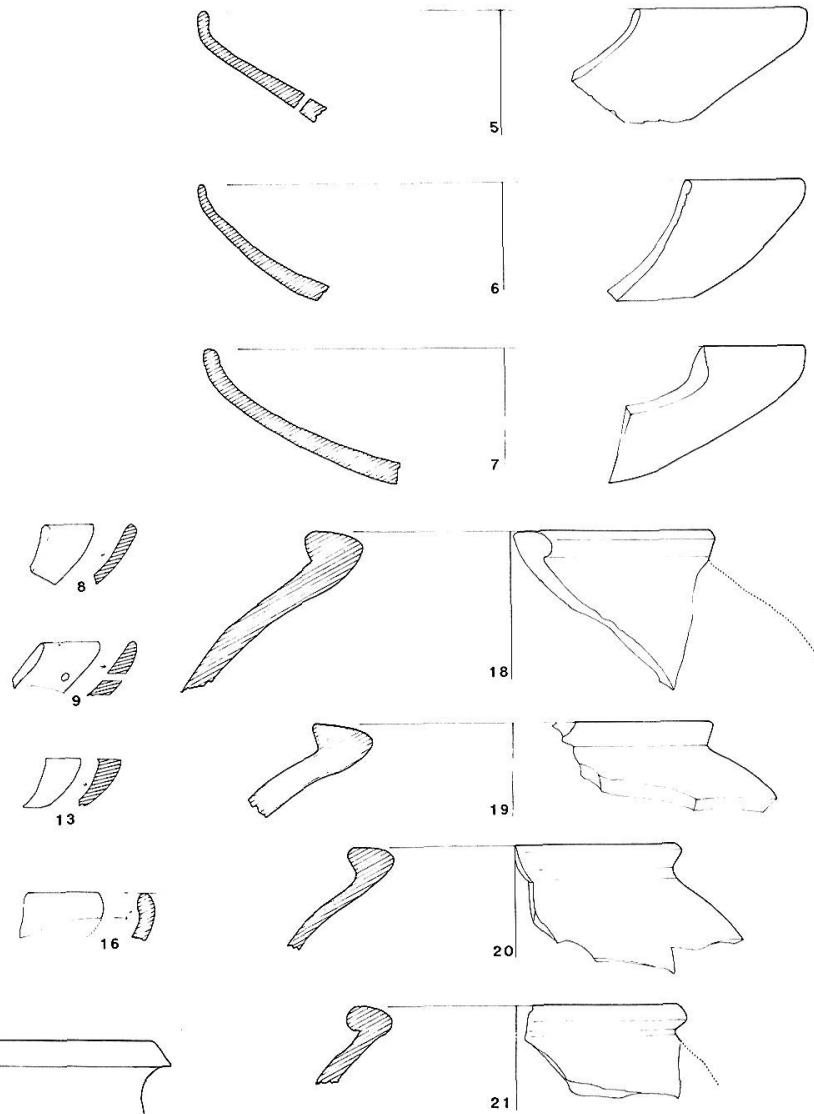

Fig. 3. Materiales de la mancha 1.
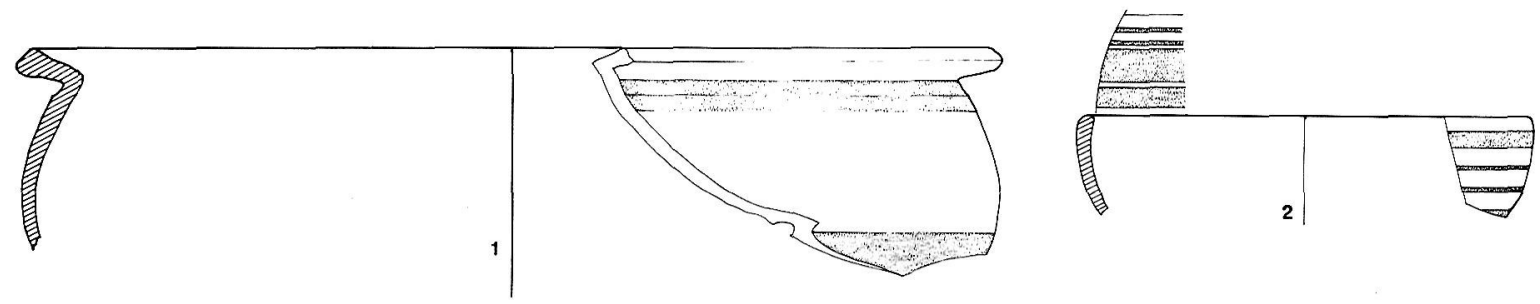

Fig. 4. Materiales de la mancha 2.

primera mitad del s. IV, aunque de forma más escasa-, nos obliga a ser prudentes; algunos bordes (Fig. 003, 14, 17) y otros con decoración de finas incisiones paralelas horizontales (Fig. 003, 15) puede apoyar la datación antigua de este conjunto.

Todo lo expuesto parece indicar, por tanto, una fecha del s. V a. C. para esta mancha cerámica; a ello contribuye tam- bién la forma de los bordes de las ánforas (Fig. 003, 18-21), con perfiles destacados de sección triangular muy similares al tipo L1 de El Oral (ABAD y SALA, 1993, fig. 157).

\section{Mancha 2}

El material cerámico es escaso y de diferente cronología. Lo más destacable son dos vasos con decoración pintada: un 

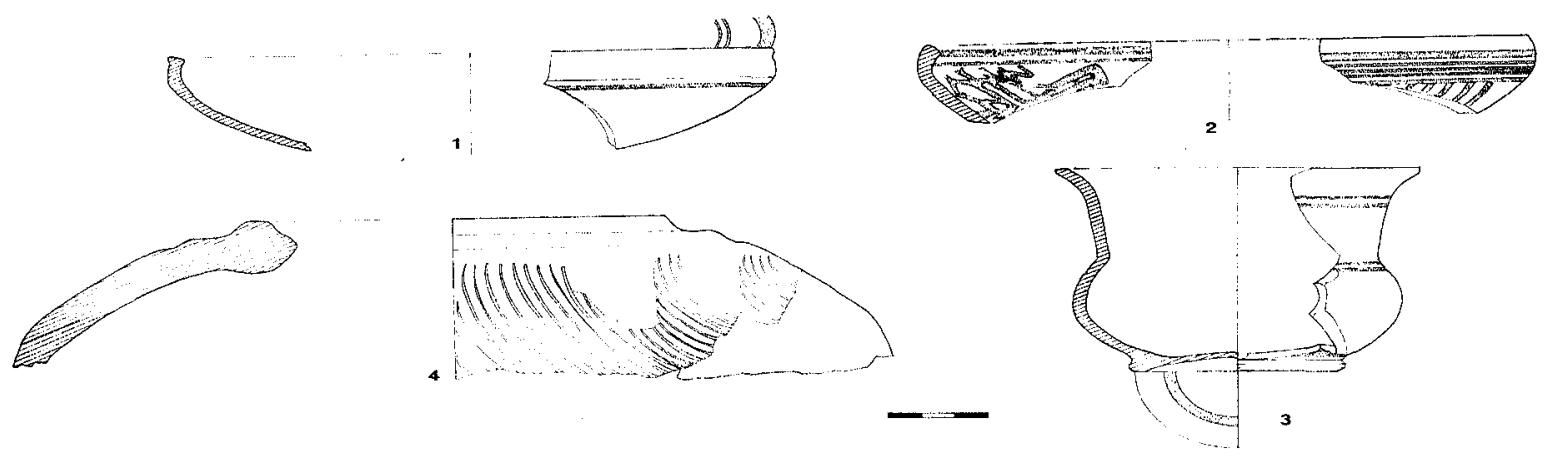

Fig. 5. Materiales de la mancha 3.

lebes de borde exvasado y labio biselado (Fig. 004, 01) bastante similar al tipo LE4 de El Oral (ABAD y SALA, 1993, fig. $159 ; 096,02,13$ ), que no se encuentra en contextos posteriores, a juzgar por su ausencia en el registro de El Puntal de Salinas (SALA SELLÉS, 1994); y un pequeño plato de cuerpo hemiesférico y borde ligeramente reentrante (Fig. 004, 02) idéntico al tipo PIB de El Puntal, que no existe en los repertorios más antiguos.

La amplitud cronológica de los escasos hallazgos dificulta la identificación de esta mancha como el resultado de una acción realizada en un momento concreto. Sin embargo, sería posible, dada la alteración del terreno previa a la actuación arqueológica, que los materiales antiguos fuesen arrastrados desde la mancha 1 , de cronología antigua y situada muy cerca de la 2.

\section{Mancha 3}

En su superficie se encontraron varias piedras de tamaño medio que podrían haber formado parte de una estructura o de una delimitación; habían sido revueltas por el tractor, por lo que no es posible confirmar esta suposición; no obstante el mero hecho de su aparición sobre la mancha de cenizas garantiza que ésta no había sido demasiado alterada por los trabajos agrícolas. Por otro lado, las formas cerámicas identificables parecen guardar también una cierta homogeneidad.

La cerámica pintada, que es la más significativa, presenta una decoración geométrica con motivos y composición complejos característica de época plena que se aplica también en el interior de los platos, algo inusual en el estilo decorativo de la época antigua. En cuanto a las formas, los bordes de los platos de casquete hemisférico dejan de ser la simple continuación de la pared de los ejemplares más antiguos para volverse ligeramente hacia el interior (Fig. 005, 1-2), un rasgo que presentan también los platos de El Puntal del tipo PIA en la primera mitad del s. IV a.C.; un vaso que aporta también referencias cronológicas es el caliciforme de la figura 005, 03 cuya forma - cuerpo bicónico, cuello alto y borde simple ligeramente exvasado - es idéntica a la de un recipiente hallado en el poblado de El Puntal, donde ha sido clasificado como el tipo CLI.

La datación de esta mancha de cenizas puede encuadrarse, pues, en la primera mitad del s. IV a.C., momento en el que ya son normales las ánforas de borde apenas destacado como la que se reproduce en la fig. 005, 04. En cuanto a los vasos cerámicos hallados en ella hay que decir que platos y caliciformes son la vajilla más frecuentemente utilizada en funciones rituales, hecho que queda corroborado por la aparición de estas formas de manera casi exclusiva en las cuevas-santuario (GIL MASCARELL, 1975, 303 ss; MARTI BONAFE, 1990). El hallazgo de estos mismos vasos en esta mancha debe interpretarse en esta línea, ya que dichas manchas no parecen ser enterramientos sino fuegos rituales $u$ ofrendas relacionadas con ellos.

\section{Mancha 4}

De nuevo es la cerámica pintada y su estilo decorativo la que nos permite establecer una cronología bastante aproximada. Destaca en primer lugar un cuenco con borde exvasado y labio de perfil moldurado del tipo «pico de ánade» (Fig. 006, 2-3), una forma bastante rara que en cambio presenta una decoración de «dientes de lobo» sobre el borde, indicativa de una cronología tardía. Otro vaso, clasificable dentro del tipo denominado por Nordstrom kraterískos (Fig. 006, 1), tiene elementos formales bastante próximos al caliciforme, pero su mayor tamaño y la presencia normal de un par de asas permiten otorgarle una identidad propia. Es frecuente en el estrato «ibero-púnico» de La Alcudia (RAMOS FOLQUES, 1990, lám. 46, 1; SALA SELLES, 1992, fig. 18, n. ${ }^{\circ}$ 58), donde aparece decorado en estilo vegetal o en estilo Elche-Archena; también se encuentra en la necrópolis norte del Tolmo de Minateda (ABAD, GUTIÉRREZ y SANZ, 1993, 145 ss), decorado en este mismo estilo figurado y asociado a cerámica campaniense Beoide y a imitaciones ibéricas de campaniense A tardía. La decoración de este vaso, que consta de dos cene- 

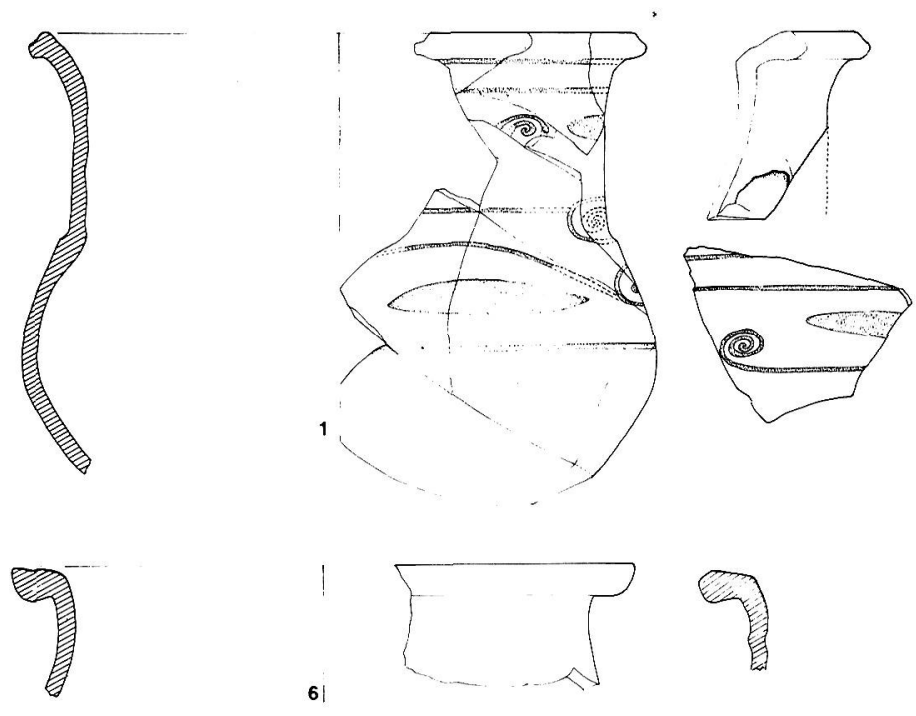

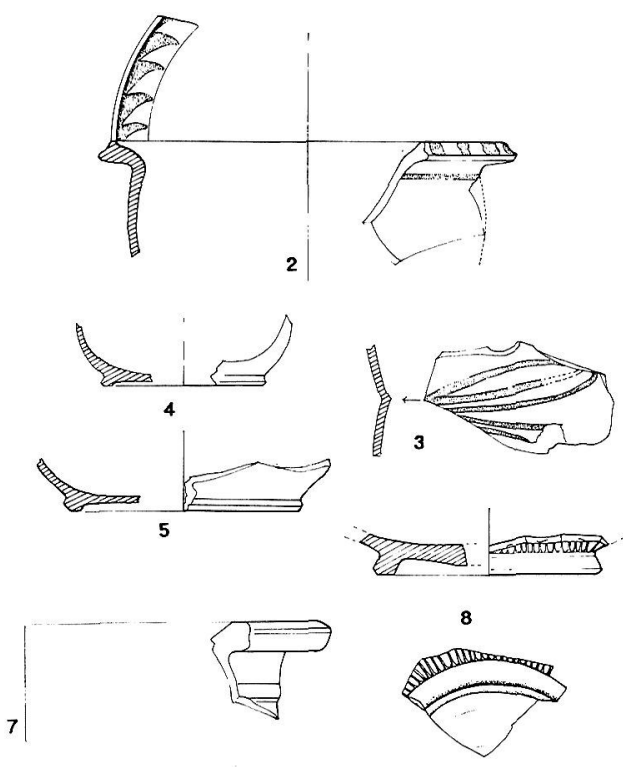

Fig. 6. Materiales de la mancha 4.

fas con sendas guirnaldas de hojas alargadas de las que parten una especie de brotes con terminación enrollada, corresponde al estilo de motivos vegetales que sustituye al de ElcheArchena en el s. I a.C.

Otros vasos confirman esta cronología de la segunda mitad del s. I a.C.: un pequeño fragmento de borde de una fuente de barniz rojo pompeyano (n. ${ }^{\circ}$ inv. 5 ), un fragmento de cuerpo de una lucerna en barniz rojo ( $\mathrm{n}^{\circ}$ inv. 7 ), y una base de sigillata itálica forma Haltern 14 (Conspectus B 3.16), posiblemente de taller noritálico, datada en época de Augusto o Tiberio (Fig. 006, 08). Hay que citar también la base de un pequeño vaso cerrado de paredes finas (Fig. 006, 5) y algunos bordes de ollas de cocina de cuello bastante vertical y borde exvasado de perfil engrosado y casi plano (Fig. 006, 6-7). Este tipo de ollas también se encuentran, y en una cantidad considerable, en la ya citada necrópolis norte del Tolmo de Minateda.

\section{Mancha 5}

Al igual que la número 3, conservaba algunas piedras junto a las cenizas, pero en esta ocasión los materiales cerámicos no mantienen un carácter tan homogéneo como en aquella; no obstante, los mejor identificables apuntan hacia una fecha tardía bastante aproximada a la de la mancha 4 .

Entre los hallazgos más significativos hay que mencionar un borde de campaniense A tardía de la forma Lamb. 28 (Fig. 007,1 ), dos fragmentos de campaniense Beoide (un fragmento de cuerpo de una pátera Lamb. 5 y un arranque de cuello, posiblemente de un vaso Lamb. 10) (Fig. 007, 2-4); un borde y cuello de ánfora Dressel IC (Fig. 007, 11), y sendos bordes de ánforas de la forma Haltern 70 (Fig. 007, 03) y del tipo Lomba do Canho 67 (n. ${ }^{\circ}$ inv. 18) (FABIAO, 1989, 65-70), ambas de origen bético y con una cronología que arranca de mediados del s. I a.C.; por último, un mortero de borde con visera y pasta norteafricana (Fig. 007, 8). La datación en la segunda mitad del s. I a.C. de este conjunto de vasos importados se compadece bien con la existencia de un lebes de borde plano decorado con una serie de «dientes de lobo» (Fig. 007, 10) y un pequeño vaso abierto de cerámica común, de pie anular y con un par de asas verticales (Fig. 007, 12) idéntico a otro ejemplar recuperado en la necrópolis norte del Tolmo de Minateda, de cronología y contexto bastante similar.

Junto a estos materiales aparecen otros vasos más difíciles de catalogar: bordes de urna sin elementos claros de datación (Fig. 007, 5, 9) y fragmentos de borde de dos pequeños vasitos de paredes extremadamente finas. Apareció también una moneda de $10 \mathrm{~mm}$ de módulo y $1,60 \mathrm{gr}$. de peso, que parece corresponder a un AE4 del siglo IV d.C., en cuyo caso habría que pensar, dada la disparidad cronológica con el resto del material, que procede del nivel superior romano arrasado por el tractor.

Esta mancha fue la única que proporcionó material óseo, todo él de origen animal (buey, ovicápridos, conejo), cuya catalogación debemos a Ana Puigcervert ${ }^{3}$.

\footnotetext{
${ }^{3}$ Cinco fragmentos de un mismo ejemplar de diáfisis de húmero de bos taurus (buey); cinco fragmentos de ovicaprino: uno de M3 superior izquierdo, otro de M3 inferior izquierdo, uno de diáfisis húme-
} 


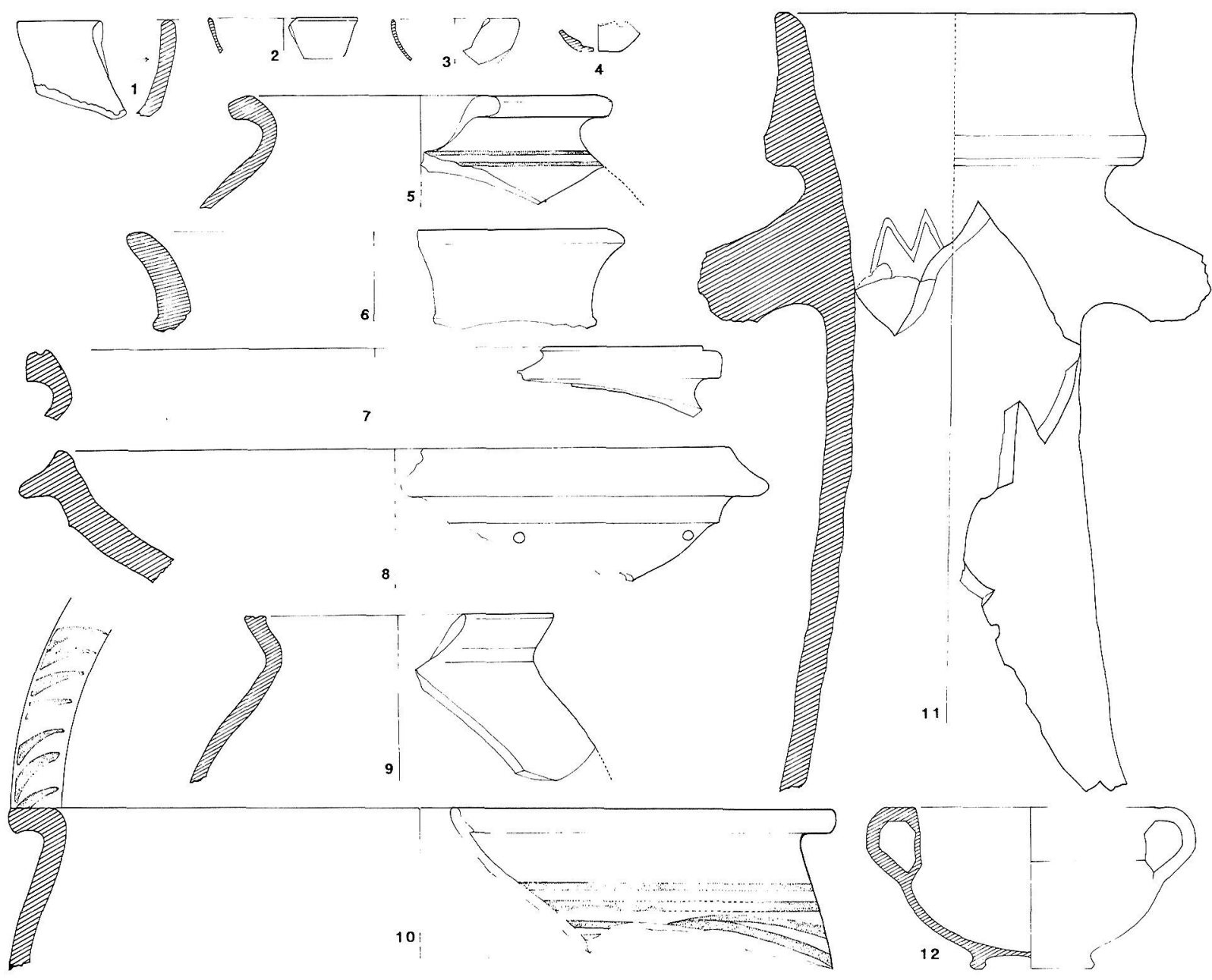

Fig. 7. Materiales de la mancha 5.

\section{Mancha 6}

Proporcionó poco material pero fácilmente identificable: la base de una pequeña pátera ática de la forma Lamb. 21/25, que asegura una datación dentro de la primera mitad del s. IV a.C. (Fig. 008,02), y el borde de un vaso pintado que, por el diámetro de su embocadura, debe corresponder a un lebes (Fig. 008, 01), aunque la identificación de su forma concreta resulte imposible; tiene en el borde una decoración de pequeños trazos paralelos que, aun siendo bastante más frecuente en

ro, uno de diáfisis fémur derecho y otro de diáfisis tibia derecha. Un fragmento diáfisis - fragmento epífisis proximal tibia izquierda de Oryctolagus cunniculus (conejo) y 25 fragmentos óseos indeterminados. los vasos de la fase antigua, todavía se aplica en algunos ejemplares de la fase plena, como se ha podido comprobar en el ajuar cerámico del poblado de El Puntal. Por lo tanto, la concordancia contextual entre la pieza ática y el lebes nos permite fechar esta concentración con bastante seguridad dentro de la primera mitad del s. IV a.C.

\section{Mancha 7}

Es la más próxima al lugar donde en su momento aparecieron las esculturas de los toros y presenta un material bastante heterogéneo tanto por su naturaleza como por su cronología.

Aparecen varios fragmentos de platos de casquete hemiesférico, entre ellos uno más completo de cerámica común, la curvatura de cuyo borde parece corresponder a modelos de época plena (Fig. 009, 01); también un fondo de otro plato de 

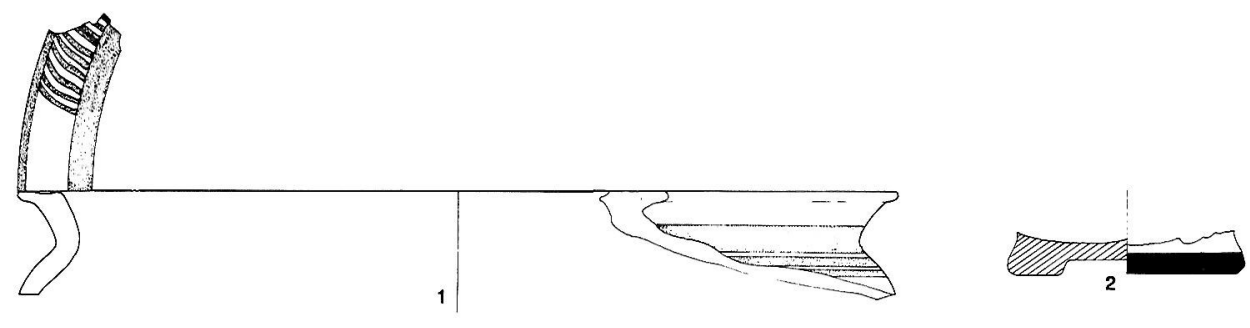

Fig. 8. Materiales de la mancha 6.

cerámica gris (Fig. 009, 02) y el pomo plano de una tapadera en cerámica de cocina (Fig. 009, 03). Todas estas piezas pueden relacionarse con el repertorio cerámico de época plena, contexto en el que también se insertaría el puente de una fíbula anular hallada en el mismo conjunto (Fig. 009, 005). Por otro lado se encontraron minúsculos fragmentos de terra sigillata ( $\mathrm{n}{ }^{\circ}$ inv. 16), una pequeña base cóncava de talón indicado que podría corresponder a un cubilete de paredes finas (Fig. 009, 04) y una base plena de cerámica común (Fig. 009, 06) que, puesto que no corresponde a la tradición alfarera ibérica, podría asimilarse a un bocal u olpe romano que sabemos llegan, junto con la cerámica campaniense primero y con la sigillata después, a algunos yacimientos ibéricos desde fines del s. II a.C. (SALA SELLÉS, 1992, 180-181, fig. 49). Apareció también una moneda muy deteriorada, de $18 \mathrm{~mm}$ de módulo y 3,67 gr de peso, cuyo grado de deterioro sólo permite identificarla como un posible semis tardorrepublicano o de comienzos del Imperio.

\section{Mancha 8}

Su material es fragmentario y poco significativo. Tan sólo merece destacarse el borde reentrante de un plato de casquete hemiesférico, decorado con filetes en el interior y con una cenefa de series oblicuas de pequeños trazos horizontales y paralelos en el exterior (Fig. 010, 02); aparecen también otros fragmentos de platos del mismo tipo (Fig. 010, 03-04), bordes de urnas (Fig. 010, 01) y bordes moldurados que parecen corresponder a una forma abierta tipo lebes (Fig. 010, 0506). Aunque con reservas, este conjunto parece de época ibérica plena.

\section{Mancha 9}

Apareció en el extremo oriental del área intervenida y bastante alejada de las demás. Entre las cenizas sólo se halló un cuenco incompleto hecho a mano, de cuerpo carenado, borde exvasado y fondo convexo, cuya forma entronca con la tradición de los cuencos carenados del Bronce Final de las comarcas meridionales alicantinas (Fig. 011).

Su hallazgo como pieza única en esta mancha es de gran interés, ya que podría ser el testimonio más antiguo de la utilización de este área con fines funerarios o sacros, utilización que se prolongaría después a lo largo del período ibérico hasta las primeras décadas del Alto Imperio. Se trataría, en este caso, del primer ejemplo de tan larga perduración documentado en la Arqueología ibérica, lo cual obliga a ser prudentes. Por otro lado, aunque en el Sureste peninsular la cerámica de cocina deja de fabricarse a mano a mediados del s. VI a.C., en el poblado de El Oral, entre fines del s. VI y la primera mitad del s. V a.C. todavía se encuentran platos de cerámica común que siguen la misma tradición formal del período del Bronce Final, si bien hechos ya a torno. En consecuencia, propondríamos una datación para esta mancha en el período ibérico antiguo.

\section{Empedrado tumular}

El túmulo, de unas dimensiones aproximadas de $7 \times 4 \mathrm{~m}$, se encontraba formado por una sola hilada de losas planas de forma irregular, dispuestas en algunos casos de manera que encajaran unas con otras, con los intersticios rellenos por piedras más pequeñas. Resultó bastante afectado por la remoción
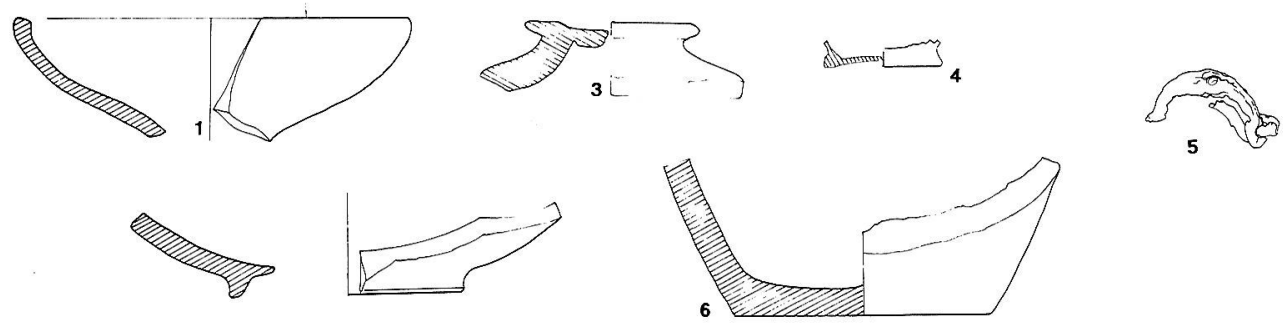

Fig. 9. Materiales de la mancha 7. 


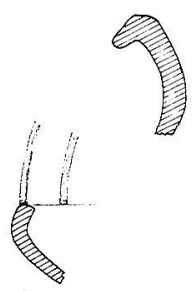

2

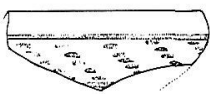

Fig. 10. Materiales de la mancha 8.

de tierras, y había perdido casi todos sus bordes, conservando sólo parte de uno de ellos, formado por piedras de menor tamaño que las interiores. Toda la tierra sobre el túmulo había desaparecido antes de nuestra actuación, y muchas de las piedras habían sido levantadas. Nuestra labor tuvo que limitarse a la limpieza de la superficie y a documentar el levantamiento de las piedras, intentando comprobar la existencia de algún elemento arqueológico bajo esta cubierta.

Sobre el túmulo se encontraron numerosos fragmentos cerámicos, aunque su relación con él, por las circunstancias antes aludidas, no es todo lo clara que debiera. Por debajo sólo se documentó una pequeña mancha gris con algunos restos cerámicos en la zona señalada en la figura 12; uno de ellos pertenecía a la misma pieza que alguno de los encontrados sobre el túmulo. Lo más lógico es suponer que este hecho fuera consecuencia de la destrucción de parte del túmulo durante el desmonte de tierras; sin embargo la parte del enlosado que cubría la zona cenicienta donde apareció la cerámica no había sido afectada por la remoción de tierras cuando pudimos estudiarla, por lo que parece que la existencia de

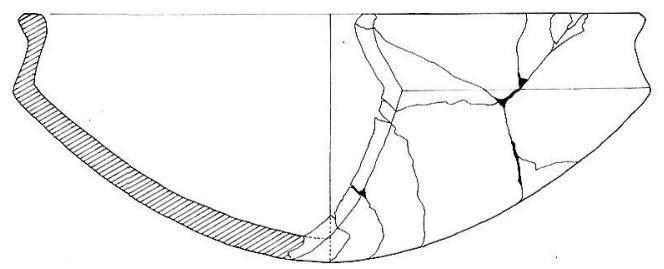

Fig. 11. Materiales de la mancha 9.

fragmentos de un mismo vaso por debajo y por encima del enlosado es un hecho intencional.

En el conjunto cerámico depositado sobre el enlosado, cuya homogeneidad no es totalmente segura, como ya hemos indicado, destaca la cerámica pintada: recipientes de almacenaje, urnas (Fig. 013, 01-04) y lebetes (Fig. 013, 05, 07-09), y es posible que el fragmento de la fig. 013,06 corresponda a un gran vaso tipo pithos o jarra pithoide; también se documentan algunos platos de casquete hemiesférico, borde simple y pie
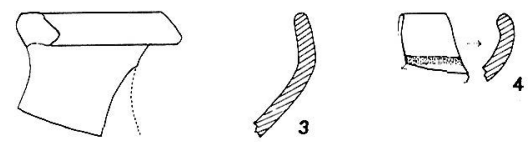

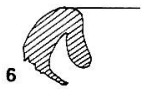

anular (Fig. 013, 10-12) y de ala exvasada (n. inv. 15 y 16) y un vasito en miniatura de cuatro $\mathrm{cm}$. de borde y dos de profundidad, con fondo cóncavo y restos de pintura en el exterior (n. ${ }^{\circ}$ inv. 34). La decoración de los vasos mencionados es de estilo geométrico y está compuesta por filetes y bandas que enmarcan círculos y segmentos de círculos concéntricos, agrupaciones de pequeños trazos horizontales o rombos; por sus implicaciones cronológicas resulta significativa la decoración con trazos paralelos perpendiculares al eje de simetría de algunos bordes de urnas y platos de ala exvasada. El conjunto mantiene una cierta homogeneidad decorativa rota sólo por el vaso de la figura 013,02 , en el que los motivos geométricos

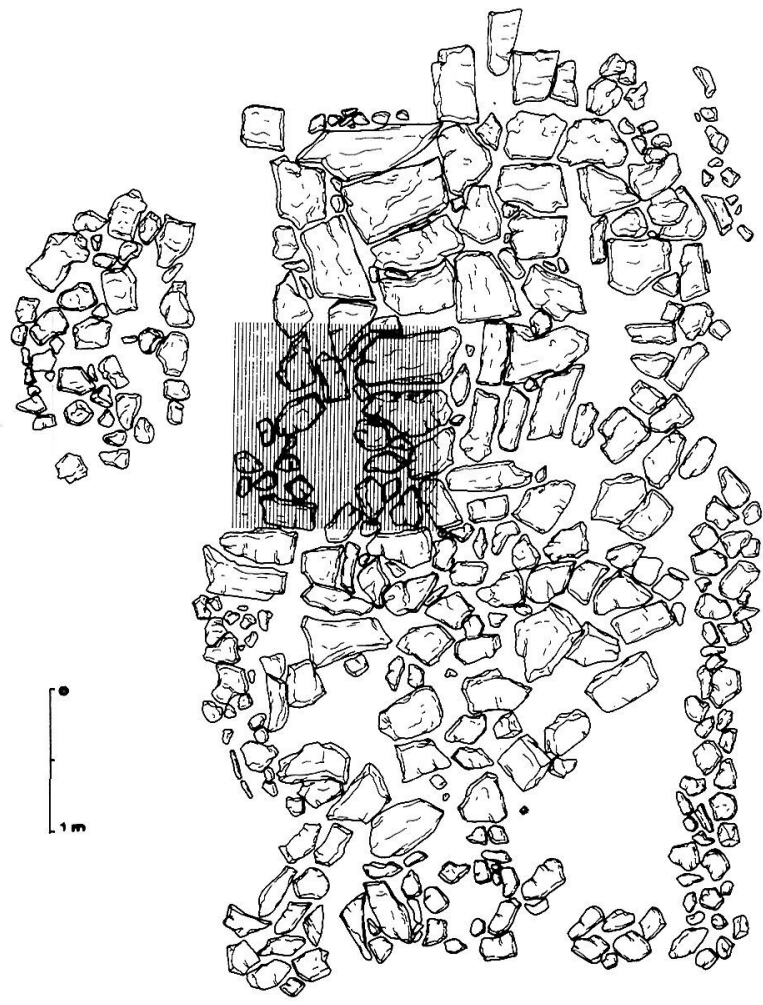

Fig. 12. Empedrado tumular. 

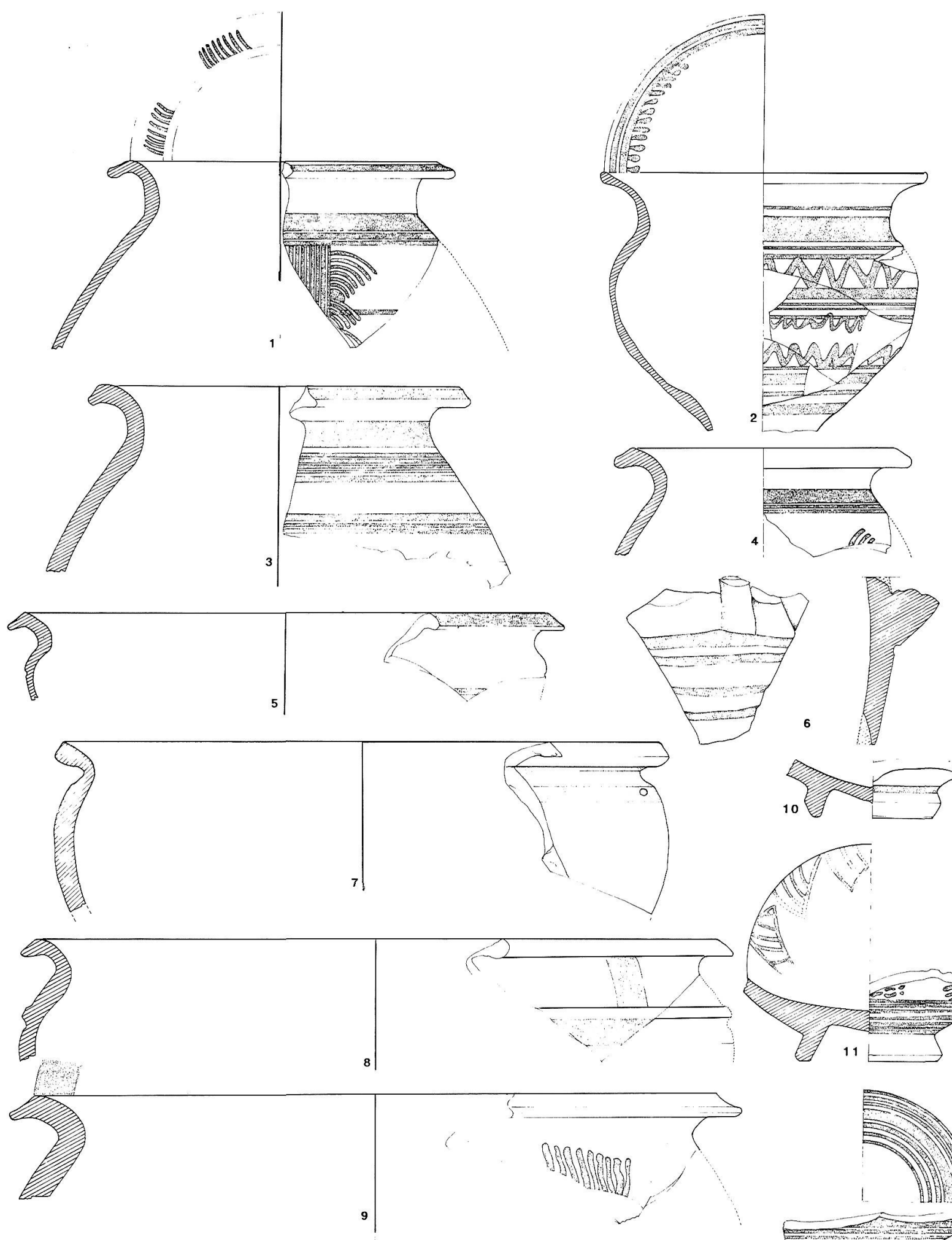

Fig. 13. Materiales sobre el enlosado. 


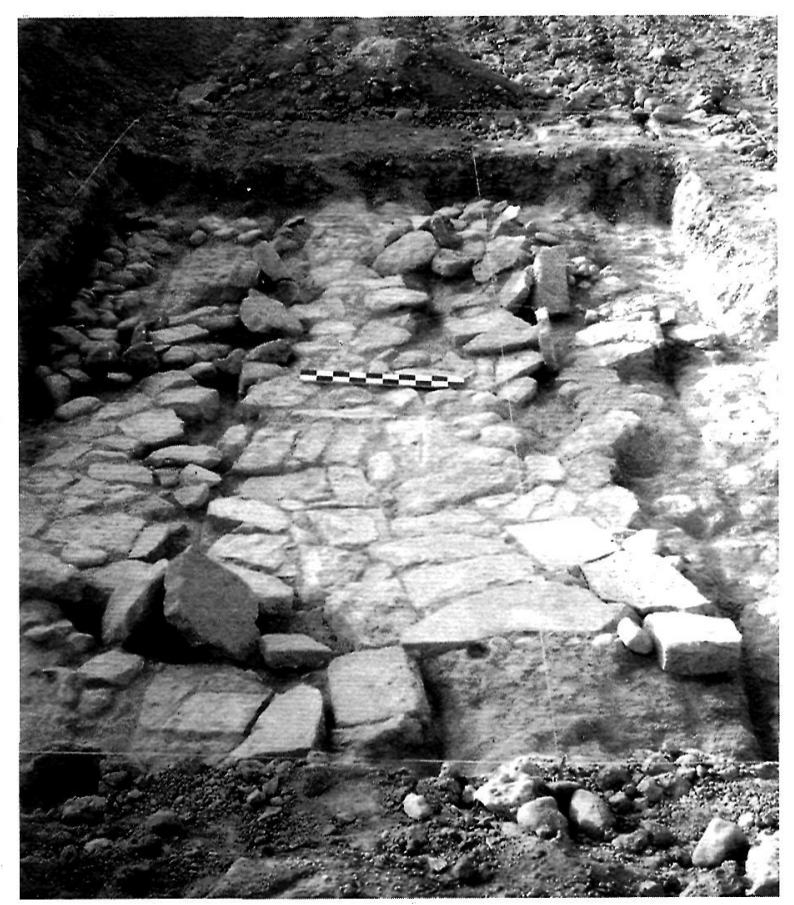

Lám. 1. Empedrado tumular.

habituales han sido sustituidos por líneas horizontales quebradas, motivo que se encuentra de forma abundante entre la cerámica pintada de La Escuera en el s. III a.C. ser el borde exvasado de un solo plato (Fig. 014, 06). También existen dos ánforas, una con borde destacado (Fig. 014,08) y otra plano (Fig. 014, 07).

El tipo de ánforas, el estilo geométrico de los vasos pintados, algunos de sus elementos formales - bordes moldurados, tendencia globular de los cuerpos de las urnas, ala exvasada de los platos - se encuentran representados en el ajuar cerámico de El Puntal con una cronología de la primera mitad del s. IV a.C.; por lo tanto, podríamos fechar el enlosado en esta primera mitad del s. IV o incluso en el último tercio del s. V, ya que todos estos rasgos formales, que ahora sabemos caracterizan los niveles del s. IV de época Plena, debieron gastarse en la segunda mitad del s. V. Existen algunas piezas a las que podría atribuirse una cronología anterior por paralelos con El Oral: el borde de la figura 014, 10, que corresponde al tipo LE6; el fondo de plato de 014, 09, que es el habitual en contextos antiguos, más frecuente que el pie anular; los baquetones. Sin embargo, el desconocimiento actual de los contextos ibéricos contestanos de la segunda mitad del s. $\mathrm{V}$ no permite asegurar ni que se trate de piezas antiguas en un conjunto posterior ni que sean rasgos formales antiguos que perduran en esa fase de transición hacia el período pleno que parece ser la segunda mitad del s. V. La decoración de líneas quebradas que encontramos en una urna es un motivo característico de fechas posteriores, por lo que habría que pensar que es la pieza más tardía de todo el conjunto; hoy sabemos, sin embargo, que en contextos del s. IV a.C. aparecen algunas decoraciones vegetales y geométricas especiales, como ovas y esvásticas, que permitirían elevar su cronología hasta esas fechas.

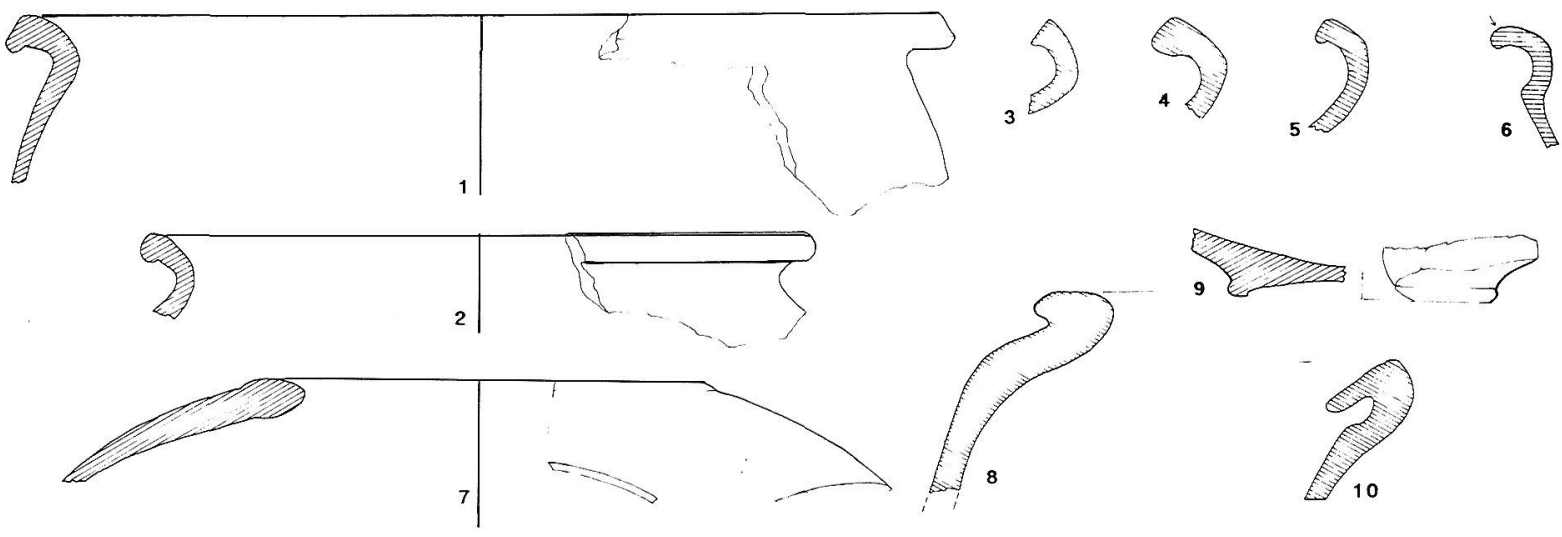

Fig. 14. Materiales sobre el enlosado.

Las mismas formas, urnas, lebetes y platos, se dan en cerámica común, en tanto que la de cocina está representada mayoritariamente por urnas (Fig. 014,01-05) y lo que parece
Contamos además con otro dato que parece apuntar una datación de época plena para el conjunto de materiales sobre el túmulo. Por debajo de las losas, en la zona sombreada en el 

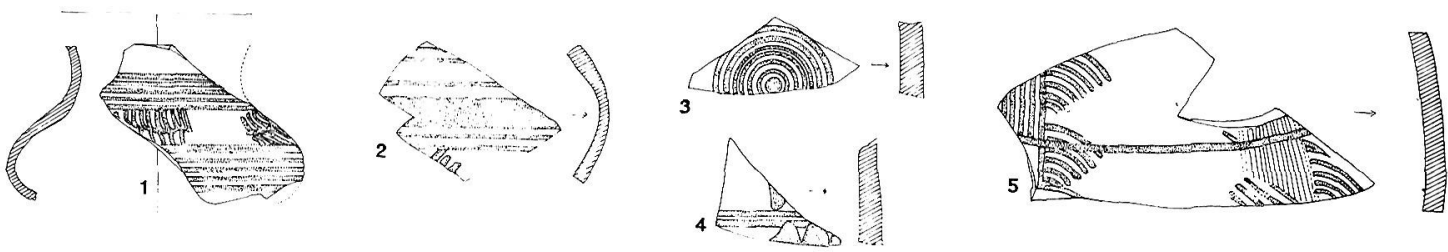

Fig. 15. Materiales por debajo del enlosado.

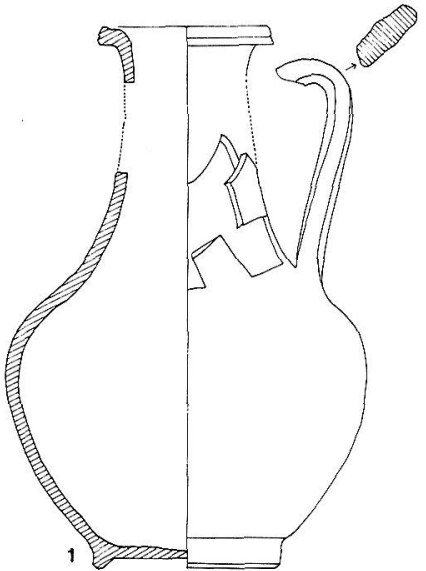

Fig. 16. Matcriales romanos.

plano, se encontraron algunos fragmentos de cerámica pintada: el más completo (Fig. 015, 01) corresponde a un pequeño vaso del tipo botella decorado con filetes y una cenefa de «melenas»; es una forma que no existe en la fase ibérica antigua y resulta en cambio relativamente abundante en época plena. Por otro lado, los fragmentos pintados informes de la figura 015, 02-05 pertenecen al cuerpo de la urna de la figura 013,01 , cuyo borde apareció sobre las losas y que tiene paralelos casi idénticos en algunas urnas de El Puntal. Por todo ello, parece que el empedrado debió construirse entre las últimas décadas del s. V a.C. y las primeras del IV a.C.

\section{ÉPOCA ROMANA}

Unos pocos fragmentos romanos se recuperaron en el perfil con una de las viñas colindantes no desfondada, en una capa grisácea a unos $45 \mathrm{~cm}$ por encima del ibérico. Los materiales recuperados son los siguientes ${ }^{4}$ :

Olpe altoimperial de producción posiblemente alicantina (Fig. 016, 01) (Abascal, 1986, 105 ss, núm. 607), de los que se han encontrado varios ejemplares en yacimientos próximos y especialmente en el paraje denominado El Campet, no muy lejos de la zona que está siendo objeto de estudio (Abascal, 1987, 364 ss).
Olla de una sola asa de cerámica común tipo Vegas 47 (Fig. 016, 02), datada entre la segunda mitad del I y el III d.C.

Terra sigillata sudgálica, forma Drag. 27B (Fig. 016, 03). Marca FUSCI en el fondo interno, en cartela alargada inscrita dentro de dos circunsferencias concéntricas. Cronología entre $5-10$ y 100-125 d.C., según Vernhet.

Fondo de lucerna, posiblemente de volutas y en cualquier caso altoimperial (Fig. 016, 04).

Aunque no son muchos los materiales recuperados, parece que se trata de un nivel altoimperial formado tras un período de abandono de las estructuras ibéricas y la elevación del terreno como consecuencia de las avenidas del Vinalopó.

\section{CONCLUSIONES}

Nos encontramos, por consiguiente, ante un conjunto de estructuras ibéricas de los siglos V a.C. a I d.C. que debieron formar parte de la necrópolis de la que proceden el monumento funerario turriforme del Museo Arqueológico de Elche

${ }^{4}$ Los autores agradecen a Antonio Espinosa Ruiz su ayuda en el estudio de estas cerámicas. Los dibujos de todo el conjunto son de Elia M . ${ }^{a}$ Alberola Belda. 
y el toro conservado hoy en el Ayuntamiento de Monforte. La coincidencia cronológica entre estos monumentos — principios del siglo V-y los más antiguos de nuestros materiales, y la cercanía de todos ellos así permiten atestiguarlo.

El empedrado tumular parcialmente documentado en nuestros trabajos debe corresponder a un monumento funerario algo más moderno que los turriformes —finales del siglo V o primera mitad del IV a.C.-, aunque no se localizó ninguna sepultura que estuviera directamente relacionada con él. Tipológicamente, el túmulo recuerda algunos de los ejemplares conocidos, como por ejemplo el de la tumba 7 de la necrópolis de Tesorico en Hellín (BRONCANO et alii, 1985, $78 \mathrm{ss}$ ), aunque en este caso conservaba más de una hilada de altura y el ajuar en su interior.

De gran interés es el conjunto de manchas excavadas, aunque no podemos asegurar que todas ellas se encontraran intactas. En ninguna se documentaron restos humanos ni hue-

\section{BIBLIOGRAFÍA}

ABAD CASAL, L., 1976-1986: «El Campet», Arqueología en Alicante, Alicante.

ABAD CASAL, L., GUTIÉRREZ LLORET, S. y SANZ GAMO, R., 1993: «El proyecto de investigación arqueológica 'Tolmo de Minateda (Hellín, Albacete). Nuevas perspectivas en el panorama arqueológico del Sureste peninsular», Arqueología en Albacete. Jornadas de Arqueología Albacetense en la Universidad Autónoma de Madrid, Madrid, 147 ss.

ABAD CASAL, L. y ALBEROLA BELDA, E., 1990: «Las Agualejas. Monforte del Cid, Vinalopó Mitja», Excavacions arqueológiques de salvament a la comunitat valenciana 1984 88. II. Intervencions rurals, Valencia, 17 ss.

ABAD CASAL, L. y SALA SELLÉS, F., 1992: «Las necrópolis ibéricas del área de Levante», Congreso de Arqueología ibérica: las necrópolis. Madrid.

ABAD CASAL, L. y SALA SELLÉS, F., 1993: El poblado ibérico de El Oral (San Fulgencio, Alicante), Valencia.

ABASCAL, J.M., 1986: La cerámica pintada romana de tradición indigena en la Peninsula Ibérica. Madrid.

ABASCAL, J.M., 1987-88: «Olpes pintados de época imperial en la provincia de Alicante», Saguntum, 21, 361 ss.

ALMAGRO, M. y RAMOS, R., 1989: «El monumento ibérico de Monforte del Cid», Lucentum, 5, 45 ss. llas de cremación, por lo que no parece que se trate de tumbas propiamente dichas. En un caso se han encontrado restos de animales y en la mayoría sólo cerámicas. Parece, por consiguiente, que nos encontramos ante depósitos de desechos de rituales funerarios relacionados con tumbas inmediatas no localizadas, tal vez porque éstas se encontraran a menor profundidad y fueran arrasadas durante el desfonde de la parcela. De su estudio se deduce que estas ceremonias se prolongaron en este lugar por espacio de cinco siglos, y que si en algún caso parece entroncar directamente, a juzgar por los materiales, con los momentos más antiguos de la cultura ibérica contestana, en otros presenta materiales de época augustea.

Tras un período de abandono, los romanos reocupan el terreno en un momento avanzado del Alto Imperio, aunque ya no como necrópolis, sino inserto en el marco del aprovechamiento agrícola intensivo que testimonian las numerosas instalaciones documentadas en El Campets.

BRONCANO, S. et alii, 1985: ' La necrópolis ibérica de El Tesorico (Agramón-Hellín, Albacete)», NAH, 20, 78 ss.

FABIAO, C., 1989: Sobre as anforas do campamento romano da Lomba do Canho (Arganil), UNIARQ, Lisboa.

GALIANA, M.F. y ROSELLO, N., 1984-85: «Catalogación y estudio de los materiales ibéricos y romanos expuestos en el Museo Arqueológico de Novelda», Ayudas a la Investigación del Instituto de Estudios Juan Gil-Aibert, II.

GIL MASCARELL, M., 1975: «Sobre las cuevas ibéricas del País Valenciano. Materiales y problemas» PLAV, 11.

LLOBREGAT, E. y RIBELLES, R., 1978: «Una tumba ibérica en la cuenca media del Vinalopó», Revista del Instituto de Estudios Alicantinos, 24 ss.

MARTI BONAFE, M.A., 1990: «Las Cuevas del Puntal del Horno Ciego. Villargordo del Cabriel. Valencia», Saguntum, 23, Valencia.

RAMOS FOLQUÉS, A., 1990: Cerámica ibérica de La Alcudia (Elche-Alicante), Alicante.

SALA SELLES, F., 1992: La «Tienda del Alfarero» del yacimiento ibérico de La Alcudia (Elche-Alicante), Alicante.

SALA SELLÉS, F., 1995: La cultura ibérica en las comarcas meridionales de la Contestania entre los siglos Vl y lll a.C. Una propuesta de evolución. Alicante.

\footnotetext{
${ }^{5}$ Ya en prensa este artículo nos llega la noticia de la aparición de importantes estructuras romanas, posiblemente una villa tardía, en un bancal inmediato al que estudiamos, actualmente en proceso de excavación. Es éste un testimonio más de la extraordinaria proliferación de vestigios ibéricos y romanos en el área del CampetAgualejas, asiento de una importante población prácticamente desconocida.
} 